\title{
CORPO E MOVIMENTO: PRODUZINDO DIFERENÇAS DE GÊNERO NA EDUCAÇÃO INFANTIL
}

\author{
Helena Altmann \\ Universidade Estadual de Campinas, Campinas, São Paulo, Brasil \\ Marina Mariano \\ Universidade Estadual de Campinas, Campinas, São Paulo, Brasil \\ Liane Apareceida Roveran Uchoga \\ Universidade Estadual de Campinas, Campinas, São Paulo, Brasil
}

\begin{abstract}
Resumo
Este artigo analisa as relações entre gênero e movimento na Educação Infantil a partir de duas pesquisas realizadas em instituições desse nível de educação em cidades distintas do estado de São Paulo. Em ambas foram feitas observações etnográficas e entrevistas, sendo que uma delas, realizada na cidade de Campinas, investigou como o corpo e o movimento eram tratados dentro da rotina escolar, enquanto a segunda, realizada em Vinhedo, problematizou as relações de gênero dentro de aulas de Educação Física. Analisamos aqui como as diferentes formas de intervenção de professores e professoras produziam relações e significados de gênero distintos durante suas aulas. Concluímos que diferentes formas de intervenção podem estimular ou não a segregação de meninos e meninas nesse espaço.

Palavras-chave: Educação Infantil. Gênero. Movimento. Educação Física.
\end{abstract}

\section{Introdução}

$\mathrm{N}$

este artigo, refletimos sobre as relações entre gênero e movimento das crianças dentro do contexto da Educação Infantil. As análises são feitas a partir de duas pesquisas com observações etnográficas em escolas de Educação Infantil, realizadas em 2007 e 2009. Situações semelhantes encontradas nas pesquisas, em diferentes escolas de Educação Infantil, levaram-nos a problematizar a constatação de que, em relação aos meninos, meninas, de um modo geral, movimentavam-se menos dentro dos espaços da Educação Infantil, além de seguirem com mais frequência as regras de "bom" comportamento estabelecidas dentro das situações escolares cotidianas.

Nas observações das duas instituições pesquisadas, destacam-se as diferenças entre meninas e meninos nas atitudes corporais e de movimento, o menor interesse das meninas pelas atividades nas aulas de 
Educação Física e a maior organização delas para a realização de atividades durante essas aulas em relação aos meninos.

Por ser, em muitos casos, um local onde a criança diariamente passa grande parte de seu tempo, a escola é um importante espaço de experiências e aprendizagens, seja no que se refere ao corpo e ao movimento ou a outras formas de conhecimento e crenças sobre o mundo em que vive.

Tal qual coloca Brah (2006, p. 342), "as desigualdades de gênero penetram em todas as esferas da vida". Pensando a escola e a Educação Física como duas dessas esferas, torna-se importante analisar o contexto concreto dessas experiências, estabelecendo relações com a produção do conhecimento na área.

Assim, neste artigo faremos uma reflexão sobre corpo, movimento e construções de gênero na Educação Infantil a partir de situações e espaços distintos: aulas de Educação Física e rotina escolar. O referencial teórico que deu suporte às nossas reflexões foram os estudos de gênero e os estudos antropológicos baseados em Geertz (1989).

\section{Metodologia da pesquisa}

As duas pesquisas consistem em estudos de tipo etnográfico ${ }^{1}$. A primeira buscou investigar como o corpo e o movimento eram tratados dentro da Educação Infantil, em uma instituição que não possuía docente de Educação Física atuando nesse nível de ensino. Já a segunda problematizou as relações de gênero dentro de aulas de Educação Física na Educação Infantil.

A primeira pesquisa foi realizada em um Centro Municipal de Educação Infantil (Cemei) localizado na região norte de Campinas (SP) e que atendia, na época da coleta de dados, crianças na faixa etária de 1 ano e 10 meses até 6 anos. Durante os meses de agosto e setembro de 2006, acompanhamos diariamente a rotina de uma sala que atendia crianças de 3,5 a 6 anos de idade (classe multietária).

O dia a dia das crianças era constituído por rotinas, as quais eram o foco das observações que tinham por objetivo entender como o movi-

1-A denominação "pesquisa do tipo etnográfica” é sugerida por André (1995), pois, apesar de esse tipo de pesquisa utilizar os mesmos instrumentos da etnografia, o tempo de permanência em campo pode variar conforme os objetivos da pesquisa e pode não ser longo como, em geral, acontece nos estudos antropológicos.

Pensar a Prática, Goiânia, v. 15, n. 2, p. 272-550, abr./jun. 2012 
mento era possibilitado dentro dos tempos e espaços da instituição. Às terças-feiras as crianças dessa turma iam até uma praça de esporte que ficava ao lado do Cemei para participarem do projeto Segundo Tem$\mathrm{po}^{2}$. Às sextas-feiras era o "dia do brinquedo", quando as crianças poderiam levar um brinquedo de casa.

A segunda pesquisa consistiu em observações de aulas de Educação Física em dois Centros de Educação Infantil (CEI) da cidade de Vinhedo (SP). As observações foram feitas entre abril e novembro de 2009. Lá, a organização das crianças nas salas de aula era feita de acordo com a faixa etária, em três níveis: maternal II (crianças de três anos); fase I (quatro anos) e fase II (cinco anos). As crianças tinham aulas de Educação Física uma vez por semana, com duração de 45 minutos cada uma. Foram observadas aulas de uma professora e de um professor de Educação Física em duas escolas, os quais também foram entrevistados.

André (1995) coloca que a investigação de tipo etnográfica, na Educação, estuda a vida cotidiana escolar e seu contexto repleto de significados. É a busca de entendimento desses significados que conduz esse tipo de pesquisa, como assevera Geertz (1989, p. 15):

Acreditando, como Max Weber, que o homem é um animal amarrado a teias de significados que ele mesmo teceu, assumo a cultura como sendo essas teias e sua análise, portanto, não como uma ciência experimental em busca de leis, mas como uma ciência interpretativa, a procura de significado.

Dessa forma, apresentaremos a reflexão traçada a respeito do gênero partindo do caso particular e estendendo para uma reflexão mais global sobre as diferenças de gênero na Educação Infantil.

\section{Corpo, gênero e movimento na Educação Infantil}

Se partirmos da concepção de que os corpos e os comportamentos são socialmente aprendidos e (re)construídos em cada cultura, pode-

2- Programa do Ministério do Esporte, em parceria com o Ministério da Educação, destinado a possibilitar o acesso à prática desportiva aos alunos matriculados no ensino fundamental e médio, principalmente em áreas de vulnerabilidade social (ver: http://portal.esporte.gov.br/snee/segundotempo/). 
mos problematizar as diferenças nas atitudes corporais de meninos e meninas em relação às regras de disciplina do corpo, movimentação nos espaços e interesse nas atividades da Educação Física.

Pensar o corpo como algo produzido na e pela cultura é, simultaneamente, um desafio e uma necessidade. Um desafio porque rompe, de certa forma, com o olhar naturalista sobre o qual muitas vezes o corpo é observado, explicado, classificado e tratado. Uma necessidade porque ao desnaturalizá-lo revela, sobretudo, que o corpo é histórico (GOELLNER, 2003, p. 28, grifos nossos).

No primeiro contexto estudado, o Cemei Pipoca ${ }^{3}$, as meninas, na maioria das vezes, eram as primeiras a seguirem as regras corporais do "bom comportamento" que, em muitas situações, consistiam em ficar paradas e/ou organizadas em fila, como mostra o seguinte trecho do Diário de campo:

Depois de 20 minutos de lanche, a professora dá a mão para duas crianças, imediatamente as outras se levantam e formam fila. Ela os leva até o local onde estão as mochilas, pede para as meninas sentarem enquanto os meninos escovam os dentes. Elas esperam sentadas, depois a professora as "libera" para escovar também. Os meninos, que já escovaram, começam a correr e escorregar pelo chão, ao vê-los, a professora pega na mão de dois meninos, em seguida, o restante forma fila, ela os leva para a sala (Diário de campo: 25/09/2006).

Esse é um exemplo de situação que, guardadas suas especificidades, repetia-se no dia a dia escolar. O fato de, naquele contexto, as meninas, mais do que os meninos, seguirem as regras impostas pode ser relacionado a uma construção histórica, na qual as possibilidades de livre movimentação foram restringidas para as mulheres, com base tanto em valores morais - meninas precisam ser recatadas para serem consideradas "boas moças" - quanto biológicos - mulheres são mais frágeis.

3-Serão usados aqui nomes fictícios para distinguir os CEIs e os Cemeis, assim como as crianças, os professores e as professoras.

Pensar a Prática, Goiânia, v. 15, n. 2, p. 272-550, abr./jun. 2012 
Goellner (2003) relata que, durante muito tempo, atividades corporais consideradas mais "pesadas", como lutas, esportes, entre outras, não eram recomendadas às mulheres em virtude de sua suposta natureza mais frágil em relação ao homem. Essa perspectiva era pautada em explicações biológicas, mais especificamente, na fragilidade dos órgãos reprodutivos e na necessidade de sua preservação para uma maternidade sadia. Com isso, o espaço privado (lar) era considerado o lugar social de domínio da mulher, onde ela "poderia exercer, na sua plenitude, as virtudes consideradas como próprias do seu sexo tais como a paciência, a intuição, a benevolência, entre outras" (GOELLNER, 2003, p.31).

Com relação às escolas pesquisadas em 2009, a situação encontrada foi semelhante. Nas aulas de Educação Física do Cei Algodão Doce, as atividades feitas no grupo das meninas aparentemente requeriam maior organização, ao contrário dos meninos. Enquanto elas organizavam filas, formavam pequenos grupos, estabeleciam regras, usavam marcações no chão para delimitar espaços, os meninos pareciam não se importar com a disposição do grupo ou do espaço. Eles transmitiam a impressão de que tudo era válido: brincavam no espaço que tivessem, como quisessem, entrando e saindo da brincadeira quando bem entendessem. Essa configuração do brincar deles pode ser traduzida pelos que estão fora da brincadeira como uma bagunça. Porém, para eles, aparentemente não havia nada de errado nisso.

Em entrevista, a professora da turma comenta a questão das diferenças de comportamento entre meninos e meninas:

Pesquisadora: Você imagina porque isso acontece?

Professora: Eu não sei. Fico imaginando às vezes pelo fato da família que diz que o menino tudo bem, o menino faz, a menina não pode se sujar, não pode ir na rua brincar... $\mathrm{O}$ menino pode ir lá na rua brincar, a menina não. A menina fica em casa quietinha, ali. A atividade das meninas geralmente é mais tranquila que a dos meninos. A deles sempre é mais dinâmica, sempre envolve mais gente do que a das meninas. As meninas são muito mais organizadas, então, na hora de você colocar uma atividade de organização, as meninas se organizam mais rápido que os meninos. Mas eu acho que os meninos se saem melhor do que elas. 
A fala da professora indica o gênero como um marcador social importante de construção de diferenças entre meninos e meninas. Tal qual conceituado por Scott (1995, p. 89), o gênero é "um elemento constitutivo das relações sociais fundadas sobre as diferenças percebidas entre os sexos, que fornecem um meio de decodificar o significado e compreender as complexas formas de interação humana". Assim, gênero é pensado como uma construção social e relacional, na qual as diferenças biológicas existentes não são descartadas, mas parte de um processo mais amplo e complexo de produção de diferenças, do qual as instituições de ensino fazem parte.

No Cemei Pipoca, em alguns momentos, ficavam explícitas as diferenças nos comportamentos corporais entre meninos e meninas. Observamos que após as refeições, meninos e meninas alternavam-se em serem os primeiros a escovar os dentes. A atitude de normalização das condutas era imposta pela professora. As meninas, na maioria das vezes, seguiam a regra, enquanto os meninos a transgrediam com mais frequência:

Terminado o lanche a professora leva as crianças para escovar os dentes no banheiro que fica dentro do refeitório, os meninos sobem em uma peça do gira-gira que está no local, logo a professora pede para eles sentarem no chão e esperarem as meninas escovarem os dentes, eles rolam no chão e brincam de cavalinho (Diário de campo: 05/09/2006).

Após o lanche a professora pega na mão de duas crianças, em seguida as outras levantam e formam fila, a professora libera as meninas para escovar os dentes, pede para os meninos esperem sentados, porém muitos ficam correndo pelo espaço. A professora diz que só vão escovar os dentes os meninos que estiverem sentados. Sem a presença da professora, os meninos correm pelo pequeno espaço em frente ao banheiro, quando ela os vê, pede para que sentem, e tal fato continua durante todo o momento da escovação (Diário de campo: 27/09/2006).

Atitude semelhante a essa também é relatada por Altmann (1998) em sua dissertação de mestrado, que analisou alunos de $5^{\circ}$ série de uma escola de Belo Horizonte (MG). A autora relata a dificuldade de meninos permanecerem sentados durante os momentos de entrada, iní- 
cio da aula e durante as instruções, discussões ou repressão da professora: "Ficar parado parecia algo extremamente difícil para os meninos, que nem mesmo sentados deixavam de se movimentar, arrastando-se pelo chão para trocar chutinhos e tapas" (ALTMANN, 1998 , p. 24). A autora conclui que naquele contexto a maneira de as meninas respeitarem as regras não era demonstração de passividade, mas sim uma estratégia de também conquistar espaço dentro da escola, ganhando, assim, a cumplicidade da professora para alcançar seus objetivos.

Muitas vezes na Educação Infantil não é permitido movimentar-se com liberdade em todos os espaços, sendo o parque e a Educação Física os locais onde essa movimentação está garantida. Pesquisa etnográfica realizada por Uchoga e Prodócimo (2008) mostrou que, no contexto estudado, havia uma normalização dos espaços que construíam regras do que era permitido e proibido realizar em cada um deles. Segundo a pesquisa, "aquilo que era considerado normal fazer em cada espaço é que determinava os locais onde as crianças poderiam correr, onde deveriam andar em fila e brincar" (UCHOGA; PRODÓCIMO, 2008, p. 226).

Assim, considerando que as possibilidades de movimentação na Educação Infantil dependem, em parte, da transgressão de normas de comportamento, aqueles que transgridem mais movimentam-se mais, obtendo assim maiores chances de aprendizagem.

Stanley (1995) afirma que a maneira mais tranquila das meninas é uma resposta à própria escola, sendo uma estratégia (intencional ou não) para ter sucesso na escola, pois essa tranquilidade é julgada tanto por elas quanto pelas professoras como positiva para o bom desempenho acadêmico. Meninos e meninas apresentam maneiras diferentes de se comportar em relação às regras, em virtude das expectativas das pessoas que compõe a escola, como também da própria sociedade, já que as crianças não chegam à escola vazias, mas já trazem uma bagagem cultural das relações estabelecidas no seu dia a dia.

No Cemei Pipoca, a professora da sala esperava delas mais calma e bom comportamento e incentivava isso através de comparações entre meninos e meninas. Isso pode ser percebido em situações do cotidiano:

14h45min A professora mostra o relógio que há na parede da sala, diz que a hora do parque está chegando e pede para que 
guardem os brinquedos sem barulho, as crianças recolhem os brinquedos fazendo bastante barulho, dois meninos deslizam por debaixo da mesa uma menina vê a vai também. A professora pede para os que já guardaram os brinquedos esperarem sentados: "Milene fica sentada!", embora haja muitas crianças que já guardaram os brinquedos de pé, a professora pede para uma menina sentar-se e ela senta, aos poucos as crianças vão sentando, duas meninas estão sentadas no chão, a professora diz "senta direitinho!", ou seja, na cadeira (Diário de campo: 14/09/2006).

Algumas pesquisas têm destacado nas suas análises a forma diferenciada como a escola trata meninos e meninas, produzindo desigualdades de gênero (THORNE, 1993; CARVALHO, 2001; FINCO, 2008).

Quanto às expectativas de docentes em relação a meninos e meninas, Carvalho (2001) analisou como professores de uma escola pública de ensino fundamental de São Paulo (SP) avaliam os bons e os maus alunos. A autora constatou que os professores e professoras esperavam atitudes mais agressivas, rebeldes e transgressoras de regras dos meninos, comportamento que não era problematizado, pois, para eles, isso seria o normal. Posteriormente, essas atitudes, antes toleradas, acabavam produzindo o fracasso escolar de muitos meninos, já que padrões de bom comportamento - não condizentes com os de meninos - eram utilizados para categorizar um bom aluno ou uma boa aluna.

Thorne (1993), em sua obra intitulada Gender play, explica que a construção social de gênero entre as crianças é um processo ativo que acontece todos os dias da vida e afirma que "as interações das crianças não são preparações para a vida, mas são a própria vida" (THORNE, 1993, p. 2). Ela realizou sua pesquisa com crianças tanto de anos iniciais de escolarização quanto pertencentes ao que no Brasil equivale ao sexto, sétimo e oitavo anos do ensino fundamental. O estudo foi feito em duas escolas norte-americanas, nos anos de 1976, 1977 e 1980, e constatou que a categoria gênero era a que mais se destacava nesses ambientes.

Os espaços e momentos reservados para as brincadeiras das crianças - ocasiões em que o corpo e o movimento se destacavam - eram, segundo a autora, aqueles em que as divisões de gênero tornavam-se mais evidentes. Nas escolas por ela estudadas, os meninos, em geral, 
ocupavam grandes áreas para jogos coletivos, enquanto as meninas ficavam com espaços pequenos. As brincadeiras de meninos e meninas eram bem separadas, e um grupo respeitava o espaço do outro sem questionar. Brincar de atividades próprias do gênero oposto geralmente não era permitido pelas crianças.

Pesquisa realizada por Finco (2008), que analisou as relações de gênero em uma escola de Educação Infantil, constatou que atitudes esperadas de meninos e meninas eram reforçadas através de gestos e palavras dos adultos que conviviam com as crianças:

A forma como a professora conversa com a menina, elogiando sua meiguice, ou quando justifica a atividade sem capricho do menino; o fato de pedir para uma menina a tarefa de ajudar na limpeza e ao menino para carregar algo torna possível perceber como as expectativas são diferenciadas para as meninas e os meninos. O que é valorizado para a menina não é, muitas vezes, apreciado para o menino e vice-versa (FINCO, 2008, p. 4).

No decorrer das observações das aulas de Educação Física no CEI Algodão Doce e no CEI Pão de Mel, pudemos notar práticas educativas que constroem e/ou reforçam as diferenças determinadas pelo sexo. Destacamos, aqui, uma sequência de falas da professora do CEI Algodão Doce 4 durante um jogo de caráter competitivo, quando várias meninas foram queimadas rapidamente e a professora comentou: "Vocês têm que tentar pegar a bola, vocês estão bobeando e os meninos estão ganhando!". E, em seguida, dirigiu-se aos meninos: "Vamos, vocês estão ganhando!" (grifo nosso).

No time das meninas, algumas se distraíram e começaram a conversar. Logo, a professora interveio: "Meninas, se vocês ficarem aí só conversando, os meninos vão ganhar! Que fofoqueiras!". E mais uma vez reforçou aos meninos: "Queima elas! Vocês vão ganhar!". Enquanto para as meninas: "Será que vocês conseguem queimar alguém?". As expressões, que aparentemente soam como formas de incentivo, têm tons e ênfases distintos quando olhadas sob a perspectiva de gênero. As falas dirigidas a elas enfatizam aspectos negativos e a falta de habilidade corporal das meninas, enquanto que quando dirigidas a eles, o incentivo ocorre de maneira positiva. Ao final do jogo, di-

4-Anotações feitas no diário de campo em 19/05/2009.

Pensar a Prática, Goiânia, v. 15, n. 2, p. 272-550, abr./jun. 2012 
ante da vitória dos meninos, a atividade foi encerrada com a seguinte fala da professora: "E os meninos ganharam! Eles foram muito espertos! E as meninas, coitadinhas, bobearam!" (grifos nossos).

Ainda que meninos e meninas estivessem realizando a mesma prática corporal, as expectativas em torno do resultado das ações para um gênero e para o outro eram diferentes. Ao perguntar para a classe se as meninas conseguem queimar alguém durante o jogo de queimada, ficou evidente a existência da dúvida quanto à capacidade delas para realizar tal feito. Pergunta semelhante direcionada aos meninos soaria redundante, já que estes, segundo expressão usada pela professora, são "espertos e fortes".

De acordo com Faria e Nobre (1997), atitudes com essas podem ser suficientes para o bom desempenho deles e o fracasso delas, inibindo diferentes manifestações na infância e impedindo que se tornem seres completos. Assim sendo, podemos pensar que as formas como meninas e meninos vão sendo educados, influencia sua formação de tal maneira que pode contribuir para se tornarem mais completos e ou para limitar suas iniciativas e aspirações e, como analisado neste artigo, suas formas de movimentação e ocupação dos espaços.

É perceptível que a dúvida na capacidade delas em alcançar o objetivo da atividade persiste em diferentes momentos e brincadeiras, assim como a certeza em relação aos meninos.

Apresentamos aqui o trecho da entrevista referente a essa questão.

Pesquisadora: Você disse que acha que as meninas não se interessam muito por chutar...

Professora: É.

Pesquisadora: E você acha que existe alguma outra diferença de interesse entre meninos e meninas?

Professora: Eu acho que os meninos são mais interessados. As meninas não tanto. As meninas eu acho que elas são mais... Elas conversam demais. Então elas gostam de ficar falando e falando, nem que seja para contar o que o fulano está fazendo de errado, do que vivenciar mesmo a brincadeira que a gente está fazendo. Elas ficam meio receosas assim de estar fazendo. Isso não é geral, logicamente. Porque tem aquelas meninas que fazem de tudo, querem ser as primeiras. O que é mais comum é as meninas não se interessarem tanto e ficarem meio receosas, dependendo da atividade. 
Podemos perceber pela fala da professora que, apesar do modo negativo como são vistas em diferentes situações ao longo da entrevista e das aulas, ainda existe uma expectativa positiva em relação às meninas, não obstante, esta só é atingida mediante um interesse por parte delas. É a partir desse interesse que elas "conseguem pensar" e "seguir as regras" como destaca a fala acima, e sobressair-se aos meninos.

Questões como essas nos remetem aos escritos de Walkerdine (1995) e seu estudo sobre a relação entre meninas e a matemática. Nessa pesquisa, a autora analisou falas de professores que tentavam explicar o tradicional fracasso de garotas e o sucesso de garotos na matemática. Diz ela:

Em suma, as garotas eram acusadas de ir bem porque trabalhavam muito, seguiam regras, comportavam-se bem. Indicadores disso eram sua atitude de obediência e o comportamento em sala de aula. [...] Em outras palavras, a aplicação das garotas ao trabalho assinalava uma série de perigos, de referências ao passado, coisas que sugeriam algo errado, algo não infantil, algo irracional, algo furtivo. Os garotos, por outro lado, podiam em realidade se sair mal, mas seu comportamento era lido como ativo, lúdico, tudo estava bem com o mundo (WALKERDINE, 1995, p. 214, grifos nossos).

Olhando pelas lentes de uma ótica cultural, na perspectiva dos estudos de gênero, não seria esse receio, essa falta de interesse das meninas apontada pela professora também produto da dúvida comumente apresentada pela sociedade quanto à capacidade delas de obterem os mesmos bons resultados atingidos pelos meninos? Afinal, já que elas têm em mente que definitivamente não são capazes de fazer algo, porque haveriam de desafiar tal regra? E quanto à forma organizada? Isso, em termos de aprendizagem, tanto na Educação Física quanto em outros momentos, é considerado algo positivo. Mas quando atribuímos a organização às meninas, não estamos dizendo que meninos devem ser desorganizados? O mesmo raciocínio pode ser posto quando colocamos que meninos são mais agitados e interessados em práticas corporais.

Por outro lado, as pesquisas desenvolvidas indicam que atitudes docentes de não segregação de meninos e meninas nas aulas contribuem para diminuir desigualdades de gênero. Nas aulas de Educação Fí- 
sica do CEI Pão de Mel, eram adotados grupos mistos e assim como em outros momentos do cotidiano escolar não foram observadas separações rígidas entre meninos e meninas. Nesse CEI, meninos e meninas não foram incentivados de maneira desigual, assim como não emergiram situações em que as expectativas em torno do resultado de suas ações divergissem. Eram comumente usadas, tanto para elas quanto para eles, palavras e expressões de incentivo, tais quais: "Vamos! Acerta ela"! (ou ele), ou "Muito bom, Camila! Na próxima dá para jogar um pouco mais longe". Além disso, o professor sempre se dirigia à classe como "crianças" e não como "alunos e alunas" ou "meninos e meninas". Ao organizar grupos para uma atividade, por exemplo, o professor afirmava: "Algumas crianças vão ficar desse lado e outras do outro". As crianças organizavam-se sem uma separação por gênero.

$\mathrm{Na}$ entrevista, quando questionado a respeito da existência ou não de diferenças nas habilidades de meninos e meninas, assim como foi feito com a outra docente que participou dessa pesquisa, registramos a seguinte resposta:

Eu acho que agora, eu diria que não. Não tem [diferença de habilidade entre meninos e meninas]. Pela idade. Porque eles estão brincando de tudo ainda. Eu acho que isso vai acontecer mais lá para frente. Acho que passa aí pela primeira fase do fundamental e na $5^{\text {a }}$ série já acontece, porque daí, elas param de brincar de umas coisas e eles também param de brincar de outras, mas por enquanto... Aqui a gente não trabalha com esporte. Não tem então essa coisa do esporte. As brincadeiras, todos eles brincam de tudo. Então, eu não percebo diferença. Tem diferença da experiência da criança, que não depende do sexo.

A fala do professor deixa a impressão de que o conteúdo esportivo tende a ser o grande vilão na construção das diferenças de gênero associadas à Educação Física e, por ele não ser, supostamente, oferecido às crianças na Educação Infantil, a contribuição que parte dessa categoria para o estabelecimento das diferenças não acontece nessa fase. De fato, tal relação já foi mencionada em alguns estudos, como os de Connel (1992) e Connel et al. (1995), que apontam o esporte como uma atividade de predominância masculina e importante para a construção da masculinidade. 
Além disso, a não percepção por parte do professor de diferenças de habilidades parece estar relacionada ao não reforço dessas diferenças nas aulas, diminuindo as desigualdades quando comparadas às aulas da outra professora.

Quando, por exemplo, uma bola é oferecida a um menino e uma boneca a uma menina, são delimitadas práticas distintas para um e para outro, baseadas em diferenças de gênero. Mais tarde, na escola ou em outro local, quando é proferida a fala de que meninos são mais agitados e habilidosos e meninas mais passivas, consideram-se estas condições inatas, e não fruto de práticas e discursos presentes nas relações sociais.

Sendo assim, não se pode deixar de considerar que, apesar do gênero não ser tido como decisivo no desenvolvimento de habilidades nas crianças da Educação Infantil, ao longo do tempo e da própria infância oportunidades distintas são oferecidas a eles e elas, desenvolvendo habilidades, interesses e gostos distintos.

Em sua experiência profissional, o professor do CEI Pão de Mel presenciou diversas situações em que as crianças opunham meninos e meninas, em diferentes aspectos. Algumas delas foram relatadas em sua entrevista, como a transcrita abaixo, a qual diz respeito aos desafios enfrentados no dia a dia, na rotina de trabalho:

Com as crianças, tem uma coisa que eu acho que é difícil... Agora nesse meu terceiro ano, estão acontecendo umas atividades com bola, chega perto de futebol, mas não é futebol. Aparece o preconceito de que é jogo para menino, daí você senta, conversa... Tem umas meninas que jogam tudo que você propõe, elas jogam de tudo. Tem uma menina da tarde, que ela só tem irmão, fica na rua o dia todo, cai, levanta, brinca de lutinha com os meninos, faz tudo. E aí, tinha uma vez que não queriam deixá-la jogar porque ela era menina. Daí senta, conversa. Depois todo mundo queria ser do time dela, porque ela é muito boa mesmo, é incrível. Então, é legal.

Nossa cultura tradicionalmente proporciona aos meninos mais oportunidades de explorar suas habilidades físicas de maneira global. Como observou a professora em fala destacada anteriormente, a sociedade permite que o menino vá "lá na rua brincar", enquanto "a menina fica em casa quietinha". As possibilidades de experimentação ofereci- 
das ao corpo são distintas, passando pelas vestimentas que cabem a um e a outro, pelos calçados, pelos brinquedos, pelas formas de expor o corpo e construir o feminino e o masculino nos meios de comunicação, entre tantos outros. Essas diferenças são produtivas, têm efeitos concretos no próprio corpo e nas suas habilidades, são formas de intervenção e podem propiciar experiências distintas, assim como estimular ou não a segregação de meninos e meninas nesse espaço educativo. Enquanto no CEI Pão de Mel a tendência à segregação era praticamente inexistente, no CEI Algodão Doce, assim como no Cemei Pipoca, ela se fazia presente. Nas escolas onde as práticas de separação eram mais intensas, também foi possível observar expectativas de características corporais e de comportamentos distintos para meninos e meninas, as quais foram aqui analisadas como produções também das práticas escolares, a partir do reforço de pequenos gestos e práticas do dia a dia na Educação Infantil.

Foi possível perceber, também, que não só o docente exerce influência sobre as crianças, mas a escola, como um todo, estimulando agrupamentos, experiências e relacionamentos distintos entre crianças, através de palavras, atitudes e ideias que transmitem ou não a concepção de separação. Porém, se de fato as ações docentes, como têm demonstrado as pesquisas, influenciam meninos e meninas dentro dos espaços educativos, podemos dizer que a formação destes quanto às questões de gênero é importante para uma intervenção de forma não desigual na prática pedagógica.

Body and movement: making difference of the gender in the early childhood education

\begin{abstract}
This paper analyzes the relations between gender and movement in the early childhood education through of two researches realized in institutions of early childhood education of distinct São Paulo cities State. At both it was done look out ethnographical and interview. The first, realized at Campinas city, search into how the body and movement's child was deal during at scholar routine. The second, realized at Vinhedo city, searched the gender's relationship in the physical education classes. We analyzing here, how the contrast interventions form of the teachers, fetch differents gender relationship during their classes. We conclude that different forms or intervention can incite or not the segregation between girls and boys this places.
\end{abstract}

Keywords: Early Childhood Education. Gender. Movement. Physical Education.

Pensar a Prática, Goiânia, v. 15, n. 2, p. 272-550, abr./jun. 2012 
Cuerpo y movimiento: las diferencias de género em la producción de jardín de infantes

\section{Resumen}

En este artículo se analiza la relación entre el género y el movimiento en el contexto de la educación infantil a partir de dos encuestas realizadas en las instituciones educativas de diferentes ciudades de São Paulo. Se efectúa em los dos observaciones etnográficas y entrevistas, una de las cuales, que se celebro em Campinas, investigaron cómo El cuerpo y El movimiento se trataron dentro de la rutina de la escuela, mientras que el segundo lugar em Vinhedo, cuestionó las relaciones de gênero dentro de las classes de educación física. Se analizan aquí cómo las diferentes formas de intervención y los profesores producido relaciones de género y diferentes significados para sus clases. Se concluye que las diferentes formas de intervención pueden estimular o no la segregación de niños y niñas en este espacio. Palabras clave: Educación Infantil. Gênero. Movimiento. Educación Física.

\section{Referências}

ALTMANN, H. Rompendo fronteiras de gênero: Marias (e) homens da educação física. 1998. 111 f. Dissertação (Mestrado em Educação) - Faculdade de Educação, Universidade Federal de Minas Gerais, Belo Horizonte, 1998.

ANDRÉ, M. E. D. A. Etnografia da prática escolar. Campinas: Papirus, 1995.

BRAH, A. Diferença, diversidade, diferenciação. Cadernos Pagu, Campinas, v. 26, p. 329-365, jan./jun. 2006.

CARVALHO, M. P. Mau aluno, boa aluna? Como as professoras avaliam meninos e meninas. Revista Estudos Feministas, v. 9, n. 2, p. 554-574, dez. 2001. Disponível em: <http://www.scielo.br/pdf/ref/v9n2/8640.pdf>. Acesso em: 4 dez. 2006.

CONNEL, Bob. "Masculinity, violence, and war". In: KIMMEL, M. e MESSNER, M. Men's lives. Nova York e Toronto: MacMillan Publishing Co. e Maxwell MacMillan Canada, 1992, pp. 176-183.

CONNEL, R.W. et al. Estabelecendo a diferença: Escolas, famílias e divisão social. 7a ed. Trad. Ruy Dias Pereira. Porto Alegre: Artes Médicas, 1995. 
FARIA, N.; NOBRE, M. Gênero e desigualdade. Cadernos Sempreviva, São Paulo, 1997. Disponível em: < http://www.sof.org.br/inst_area_atua_fem_texto_esc.htm>. Acesso em: 11 jun. 2009.

FINCO, D. Socialização de gênero na Educação Infantil. In: SEMINÁRIO INTERNACIONAL FAZENDO GÊNERO: CORPO, VIOLÊNCIA E PODER, 8., 2008, Florianópolis. Anais..., Florianópolis: UFSC, 2008.

GEERTZ, C. A interpretação das culturas. Rio de Janeiro: Koogan, 1989.

GOELLNER, S. V. A produção cultural do corpo. In: LOURO, G. L.; NECKEL, J. F.; GOELLNER, S. V. (Org.). Corpo, gênero e sexualidade: um debate contemporâneo na educação. Petrópolis: Vozes, 2003. p. 28-40.

SCOTT, J. Gênero: uma categoria útil de análise histórica. Educação e Realidade, Porto Alegre,v. 2, n. 20, p. 71-99, jul./dez., 1995.

STANLEY, J. El sexo y la alumna tranquila. In: WOODS, P.; HAMMERSLEY, M. Género, cultura y etnia en la escuela: informes etnográficos. Madrid: Ministério de Educación y Ciencia, 1995. p. 49-63.

THORNE, B. Gender play: girls and boys in school. Piscataway: Rutgers University Press, 1993.

WALKERDINE, V. O raciocínio nos tempos pós-modernos. Educação e Realidade, Porto Alegre, v. 20, n. 2, p. 207-226, 1995.

UCHOGA, L. A. R; PRODÓCIMO, E. Corpo e movimento na Educação Infantil. Motriz, Rio Claro, v. 14, n. 3, p. 222-232, jul./set. 2008.

Recebido em: 10/11/2010

Revisado em: 22/02/2011

Aprovado em: 10/07/2011

Endereço para correspondência

altmann@fef.unicamp.br

Helena Altmann

Universidade Estadual de Campinas

Pensar a Prática, Goiânia, v. 15, n. 2, p. 272-550, abr./jun. 2012 
Faculdade de Educação Física

Departamento de Educação Física e Humanidades.

Av. Érico Veríssimo, 701

Cidade Universitária Zeferino

13083-851 - Campinas, SP - Brasil - Caixa-Postal: 6134 